\title{
Phenomenology and the price of beans
}

\author{
Dennis Flannery, Consultant Psychotherapist, The General Infirmary at Leeds
}

Psychiatry might be seen as a three dimensional space, with two of its dimensions caricatured in the title. Of the first, 'phenomenology' stands for scientific rigour, the medical view favouring diagnosis based on analytical activity, followed by construction of syndromes from individual symptoms/ measures. The 'price of beans' stands for materials; the economics of care in the post Griffiths era, value for money, hospital closures, massive reorganisation and the negative implications for service users.

To the third, oldest (at present) least wellpublished dimension, I will refer anon.

\section{General management}

Early in the 1980s, an old concept was exhumed, given fashionable status and 'reheated' by central government and some well-meaning agents of change in psychiatry. It was and is community care or to give it its proper title 'care in the community'. The atmosphere was favourable for two reasons; the Mental Health Act had undergone revision and additional safeguards for patients' freedoms were enshrined, assuming more community-orientated care; the Conservative government was in its second term, committed to lower public spending, value for money etc. Despite later ministerial protestations that it was never expected that money would be saved by closure of large mental hospitals, I remain unconvinced that this was not an early motive for community care replacing mental hospitals, in the minds of Ministers and mandarins.

As an enthusiastic general psychiatrist with a little management experience in a unit management group I was moved in 1984-1985 to prepare myself for general management in order to defend psychiatric budgets, ensure the orderly development of new services and attend closely to quality of care, training plus the hospital-community shift, within a caring philosophy.

When the post for which I had prepared myself was established, the Unit contained mental handicap, geriatrics, community services (district nursing, health visitors) and psychiatry. I was appointed in 1986 to the apparent approval of some and disdain of others (especially medical colleagues!)
It became apparent early in my general management career that real cuts were required of our small, RAWP-gaining district under the guise of cost improvement. The earlier Hotel Services competitive tendering had led to grave laundry problems, domestic services were slow to achieve pre-privatisation standards and the in-house caterers struggled to maintain quality within the new tight financial arrangements.

Despite the 'priority services' image of my unit, after ten months in post it became clear that even my unit was to be subjected to 'cost improvement', in order to balance the district's books in 1987-1988. The acute unit was hit much harder and even the most enthusiastic of Griffiths' protegés could not pretend that services to patients would be unimpaired by the process.

The Griffiths model of general management has been uncritically applied to the Health Service as if 'value for money' and 'quality assurance' could compensate for under-funding, shortage of trained professionals and lack of control on agency profiteering. Because funding is now grossly inadequate, care in the community cannot proceed in an orderly way; local experience resulting from non appearance of regional bridging finance retained patients in hospital two years after a mature plan for their rehabilitation and community residence had been approved by health and local authorities. Regional officers were not in a position to advance the necessary sums to allow social services developments to proceed, because of competing regional priorities like computerisation and supplies centralisation.

Somewhat aside of psychiatry, an extremely modest incontinence service was planned for 19871988 with funding raised from internal unit redeployment and a sum generated at district level from cost improvements (anticipated). Two nurse advisers, a clinical assistant session, equipment and enhanced disposable budgets plus secretarial support were secured. Within weeks of the nursing posts being approved locally, regional supplies policy rendered the district's problems measurably greater, by the simple substitution of a different, cheaper absorbent material as their standard issue to patients requiring incontinence pads. It did not work as well and previously contained urine began to leak. General Management or Gross Miserliness? 


\section{Science?}

Turning to the influence of phenomenology, young psychiatrists are now encouraged to make detailed phenomenological assessment of patients' utterances. Is there an 'as if' quality? Are the thoughts broadcast? Do the hypochondriacal preoccupations amount to delusion? One effect of the process is to distance the doctor from his patient. What most concerns him is the utterance/phenomenon, not the individual making it or its meaning for him $/ \mathrm{her}$. Psychiatry more and more emulates the scientific evidence gathering and analysing approach of other mature medical specialities, but without an adequate scientific base. Phenomenology is not natural science and decisions based upon the approach cannot be compared with the treatment plan arrived at following physiological or biochemical investigation. In specialties like surgery or endocrinology, hard evidence can guide treatment in the presence or absence of adequate "I-Thou" encounter. In psychiatry, it is much less clear that phenomenology can offer similar assurance, but the discipline continues in favour despite its clear limitations.

A young amphetamine abuser had psychotic symptoms and assembled psychiatrists (old and young) debated the hallucinations, 'as if' and thought disorder. The patient did not attend this debate but was clearly distressed and disorganised at interview earlier, elaborating a long history of similar experiences. The relevance of early life with parents was linked at interview to current difficulties but was not explored in the treatment discussion.

\section{The politics of psychiatry}

How can psychiatry and psychiatrists improve the lot of patients? The demise of the mental hospital may reduce the incidence of institutionalisation, but I doubt that factor will carry much benefit in terms of reducing long-stay needs. It will also reduce the number of staffed beds for dependent people, who may or may not also reduce in number. There is urgent need for psychiatrists to examine critically future provisions planned to replace mental hospital beds, before health authorities grant approvals and local authorities take up funding. "Care in the community' is a lofty principle. If it is to succeed, I believe it must cost $30-50 \%$ more than long-stay hospital care. No such additional funding is forthcoming from statutory sources. I calculate a $20-30 \%$ drop in service as a result of the closures planned, unless additional resource is provided.

The 1960s to early 1970s was a time of relaxed formalities and individual freedoms. Much of the result was undesirable; the family became a shaky institution, young people lost sense of belonging and turned to drugs and mysticism. However, there was opportunity for the eccentric, bizzarre, former outcast to be valued as another respected human being. The 1980s have seen regression in this process, the individual is respected so long as he achieves in establishment terms; deviation or inadequacy no longer meets with tolerance, tensions in society are high. Psychiatry itself has moved with the times and distanced itself from the mood of human contact and mutual respect which characterised the 1970s.

\section{All you need is love?}

The third dimension in my 3-D structure could be termed 'human touch'. In Robert Pirsig's terms, ${ }^{1}$ it would be the romantic aspect of life which balances the classical. Carl Rogers ${ }^{2}$ would refer to the visceral elements which balance the cerebral and in group terms, ${ }^{3}$ one might talk of the maintenance function required for adequate application to the task.

Having left general management for full-time psychotherapy work, I recognise more clearly than ever the pressures on professionals and consumers resulting from not just Griffiths, but also society's current 'help thyself' ethos. A final anecdote indicates that Sainsbury's has problems with its slick management also. I have shopped at one of their newer stores for two to three years. Of late, standards have slipped. Rapid scanning of goods requires less staff time at checkouts and stick-on labels are no longer used. This is all cost improving. However, I was recently infuriated by the arrival of tins and bottles on top of my bread and tomatoes at the Saturday morning ritual. When I complained, the obviously stressed checkout operator reported to her supervisor that I was 'moaning' and the supervisor plus manager had little comfort for me. I regard this incident as symptomatic of the inevitable dehumanisation which accompanies relentless, singular pursuit of efficiency. Sainsbury's computer, the NHS planning cycle, value for money are all very fine in principle but, in some respects, machines and mechanisms have become cleverer, slicker than the people who have to use them and be accommodated. Let us not forget that confusion in the patient leads to confusion in the doctor and if the system feels bad for providers and consumers, it probably is bad whatever Sir Roy Griffiths, Mr Moore or Mr Lawson would have us believe.

\section{Never mind the width}

At the same time as we require better resources from our paymasters, let us not forget also that our responsibility as professionals is not mitigated by financial constraints. It is incumbent upon me as a service provider to ensure that, not only do I make the correct assessment of the patient's need/diagnosis/formulation, but that my patient leaves me 
more, not less, satisfied. If there is a lesson for psychiatry to learn from good managers, I believe it should contain reference to quality, consumer satisfaction and external service monitoring. We should be encouraging advocacy, $\mathrm{CHCs}$, Mind and other groups to supply feedback. Most of all, we should ensure that dissatisfied consumers have an easy means of registering their impressions in an appropriate place, whether dissatisfaction is with inadequate material resource or with lack of human understanding. Let us not as professionals attempt to hide behind the excuse of general management and resource constraint, but if we are sufficiently confident of our own professionalism and accountability to the consumer, we will actually provide a lead for general managers in service structuring and provision. The image of consultants generally, in the Health Service, is not of over-worked, highly con- scientious, totally committed professionals, but has a strong flavour of the over-paid, with loyalties to private sector and maximum income, leaving barely acceptable time and commitment for NHS patients. Unless the medical profession in psychiatry and other specialities provides a credible lead in NHS quality and planning, the dismantling of the structure, accomplished by highly competent general managers, not committed to the welfare state, will not be far away.

\section{References}

${ }^{1}$ PIRSIG, Robert (1974) Zen and the Art of Motorcycle Maintenance. London: Bodley Head.

${ }^{2}$ Rogers, CARL R. (1951) Client-Centered Therapy. Boston, MA: HM.

${ }^{3}$ NAPIER, R. W. \& Gershenfeld, M. K. (1973) Groups: Theory and Experience. Boston, MA: HM. 